1

2

3

4

5

6

7

8

9

\title{
Planetary well-being
}

\section{Author information}

JYU.Wisdom community*, Teea Kortetmäki**, Mikael Puurtinen, Miikka Salo, Riikka Aro, Stefan Baumeister, Rémi Duflot, Merja Elo, Panu Halme, Hanna-Mari Husu, Suvi Huttunen, Katriina Hyvönen, Sanna Karkulehto, Saana Kataja-aho, Kirsi E. Keskinen, Johanna Maksimainen, Tuuli Mäkinen, Annukka Näyhä, Mari-Anne Okkolin, Tommi Perälä, Jenna Purhonen, Kaisa J. Raatikainen, Liia-Maria Raippalinna, Kirsi Salonen, Katri Savolainen, Janne S. Kotiaho

* This paper is a result of a collective effort and intense transdisciplinary discussions by the JYU.Wisdom community. All authors contributed to the work significantly and are listed in alphabetical order, except for the first three and the last author, who are together considered as the shared first author.

School of Resource Wisdom, P.O. Box 35, 40014 University of Jyväskylä, Finland

Department of Biological and Environmental Science,

Department of History and Ethnology

Department of Music, Art and Culture Studies

Department of Psychology

Department of Social Sciences and Philosophy

Open University of University of Jyväskylä

School of Business and Economics

Department of Geography and Geology, Geography Section, University of Turku, Vesilinnantie 5, FI-20014

Turku

Gerontology Research Center and Faculty of Sport and Health Sciences, University of Jyväskylä

** Corresponding author: teea.kortetmaki@jyu.fi 
29 Planetary Well-Being

\section{ABSTRACT}

31 Tensions between the well-being of present humans, future humans, and nonhuman nature manifest in social protests and political and academic debates over the future of Earth. The increasing consumption of natural resources no longer increases, let alone equalizes, human well-being, but has led to the current ecological crisis. While the crisis has been acknowledged, it is often approached in human-centred terms, with framings that limit the moral worth of nonhuman nature to its contribution to human well-being. We derive and propose the concept of planetary well-being to recognize the moral considerability of both human and nonhuman well-being, and to promote transdisciplinary, cross-cultural discourse for addressing ecological and social crises and for promoting societal and cultural transformation. Conceptually, we shift focus in well-being from individuals to Earth system and ecosystem processes that underlie all well-being. Planetary well-being is a state where the integrity of Earth system and ecosystem processes remains unimpaired to a degree that species and populations can persist to the future and organisms have the opportunity to achieve well-being. After grounding and introducing planetary well-being, we shortly discuss how it can be measured and reflect upon its potential as a bridging concept between different worldviews.

\section{INTRODUCTION} human impact, and by 2050 this area is projected to shrink to less than $10 \%$ (IPBES 2018; Watson et al. 
production (IPBES 2019; Díaz et al. 2019). During the last five decades, the population sizes of vertebrate animals have declined on average by $68 \%$ (WWF 2020), wild mammal biomass by $82 \%$ (IPBES 2019), and it is projected that by 2050 humans will have eliminated $38-46 \%$ of all biodiversity (measured as mean species abundance) from the planet (van der Esch et al. 2017; IPBES 2018).

Human actions threaten to cause irreversible changes in the Earth system, with critical safety limits (planetary boundaries) exceeded for biosphere integrity, biochemical flows, climate change, and land system change (Rockström et al. 2009; Steffen, Richardson, et al. 2015; O’Neill et al. 2018; IPCC 2019). Crossing such boundaries may lead to irreversible changes in the Earth system (Steffen et al. 2015b; O'Neill et al. 2018). The scale of these pressures has evoked a proposal for labelling the current geological epoch the Anthropocene, an era where humans shape the geo- and biosphere evolution (e.g. Crutzen and Stoermer 2000; Dryzek and Pickering 2018). The negative anthropogenic impact on the Earth system has thus reached a point where the future of human societies and the flourishing of life in general are threatened.

On the other hand, attributing the aforementioned negative impacts to the whole of humanity, 'Anthropos', is overgeneralizing: it dismisses that only a fraction of the humanity is historically responsible for most of the environmental harm and that the extent of harmful impacts varies significantly depending on particular processes of production and consumption (Malm and Hornborg 2014). According to the historical graphs, these developments have "been almost entirely driven by a small fraction of the human population, those in developed countries" (Steffen et al. 2015a).

Global inequalities among humanity are stark regarding who receive the benefits of environmentally damaging actions and who have to bear their detrimental impacts. Around the world, nations' top $10 \%$ earners capture $37-61 \%$ of national income; globally, the share of the top $10 \%$ of global income is between 53-60 \% depending on the method of measurement (Alvaredo et al. 2018). The costs of ecosystem 
71

72

73

degradation and climate change, on the other hand, hurt the well-being of at least 3.2 billion less affluent people (IPBES 2018; UN Environment 2019). Retaining the present standard of living in the wealthiest countries necessitates structures that maintain globally unequal, exploitative labour division and ecological exchange (Hornborg 1998; Newsome et al. 2015). Transformative changes to social, economic, and technological systems are increasingly called for to change the course towards more sustainable future in both environmental and social terms (e.g. Díaz et al. 2019; Kohler et al. 2019; Willemen et al. 2020).

The environmental and social problems described above have generated a broad spectrum of discourses and action, from the sustainable development framework and goals (UN General WCED 1987; Assembly 2015) to the foundations of social justice (Nussbaum and Sen 1993) (for key frameworks, see the Supplementary Box). From the ecological viewpoint especially, a serious challenge is that a majority of the frameworks focus on human perspective and consider nonhuman well-being important only to the extent it contributes to human well-being (e.g. Dryzek 2005, p. 157). Solely human-concerned ethos of many conceptualisations of sustainability is typical of Western science, contrary to some other knowledge systems (e.g. some forms of indigenous and local knowledge) that emphasize balance and collaboration with nature (Díaz et al. 2015).

Another challenge with the existing frameworks is that they seldom focus on the systems and processes that support life, well-being, and biodiversity at different spatial scales. Although sustainability studies have recognized the interconnectedness of the social, economic, and ecological aspects of life, and the importance of studying processes as taking place in complex socio-ecological systems (Ostrom 2009), the mainstreaming of such thinking to well-being studies has been slower. Lack of a systems-oriented and multi-scalar outlook can result in a fragmentary view to the problems and their solutions. Many frameworks presented in Box 1 aim to overcome either anthropocentrism, or the lack of systemic and multi-scalar outlook, but few attempt both. 
94 The need to conceptualise well-being in a way that is non-anthropocentric and encourages systems-

95 oriented, multi-scalar outlook, raises a fundamental question: what is well-being? In human psychology, the

96

97 focus is traditionally on subjective, experienced well-being: persons with subjectively high well-being are satisfied with life, experience positive feelings, are able to fulfil personal aspirations, have favourable relations, and are in good mental health (Keyes 2005; Kokko et al. 2013). Ecopsychology argues that human beings are simply a part of nature (Winter and Koger 2004). From this perspective, nature and humanity are ineradicably linked and high levels of well-being can only be achieved through the experiential realization of nature connectedness and exposure to nonhuman nature (Roszak et al. 1995; Mayer and Frantz 2004;

Brymer et al. 2010). On the other hand, the focus on subjective well-being is problematic from the viewpoint of social justice and equality. Underprivileged people can adapt to their circumstances (demonstrating 'malleable preferences') and may be unable to articulate their experiences of lower wellbeing and satisfaction of life, whereas minor losses of the privileged groups can get overemphasized (Nussbaum and Sen 1993; Nussbaum 2011). The subjective accounts of well-being have also been criticized from the environmental sustainability viewpoint: if experienced well-being depends on the fulfilment of seemingly limitless human desires and wants (instead of limited needs), this poses unsustainably high material criteria for well-being (Gough 2015).

In social sciences, consequently, well-being is often understood to depend on the satisfaction of basic human needs, such as the need for material subsistence, protection, affection, understanding, and autonomy, which contribute to physical and mental health, and to the abilities for social participation (e.g. Doyal and Gough 1984; Rice 2013; Gough 2017; see also Nussbaum and Sen 1993). The argument is that these universal human needs persist through cultures and time, even while the strategies and means to satisfying the needs, and thresholds for adequate needs satisfaction, can change.

The needs-based, objective accounts of well-being are also used in the context of nonhumans, since studying their experienced well-being is challenging (Wemelsfelder 1997). Most of the literature on 
nonhuman well-being focuses on nonhuman animals and maintains that they have species-typical physical and behavioural needs, the satisfaction of which is crucial for their well-being (e.g. Broom 1991; Bartussek 1999; Singer 2002; Nussbaum 2006). The concept of well-being (also referred to as thriving or flourishing) has been applied to other organisms, populations, species or lineages, and ecosystems, too. Ecosystem well-being, for example, has been defined as the functional integrity of an ecosystem and its capacity to retain its typical functionings and characteristics (Schlosberg 2007; Kortetmäki 2017; see also Prescott-Allen 2001), including succession and adaptation. The well-being of species or lineages is addressed via needs: to be well, species must be able to maintain self-sustaining capacities and to adapt to environmental changes (Kortetmäki 2018).

We propose a new concept, planetary well-being, to address the above discussed need for a nonanthropocentric, systemic conceptualization of well-being that takes into account the multiple scales of interaction. Planetary well-being acknowledges the value of both human and nonhuman well-being for their own sake: the moral right for both humans and nonhumans to exist, to have their needs satisfied, and to realize their typical characteristics and capacities. The needs of organisms - both human and nonhuman are interconnected so that the satisfaction of the needs of various entities creates both synergies and conflicts. Hence, the concept transcends the level of individual organisms and focuses on the integrity of Earth system and ecosystem processes underlying the well-being of all forms of life. It also serves as a framework that ties together ecological and social equality crises. As a concept, planetary well-being facilitates scientific and political discussions by using the same vocabulary to address the impacts of human activities on the well-being of human and nonhuman nature.

To derive and propose a non-anthropocentric concept means that we openly commit to certain normative views on moral considerability. Morally considerable beings and collectives have moral value for their own sake (inherent value), regardless of whether they have instrumental value for humans. Consequently, the well-being of morally considerable entities matters for their own sake. We adopt a pluralist or multi-criterial 
142 approach to moral valuation; it grounds the moral considerability of entities on several criteria (Warren 1997). The pluralist valuing grants moral considerability to human and nonhuman individuals but extends

144 the sphere of moral considerability beyond them: species or lineages and ecosystems that can be well or

145 flourish and have self-regulative capacities (e.g. Rolston 1985, 2002; Schlosberg 2007) are also morally

146 considerable (hereafter, the term 'living entities' denotes this diverse ensemble of morally considerable

147 entities). While our normative viewpoint may not be shared by all, we believe that responding to ecological

148 crisis adequately requires adopting a non-anthropocentric approach where nonhuman nature is valued also

149 for its own sake, not only due to its importance for human prosperity.

\section{CONCEPTUALIZATION OF PLANETARY WELL-BEING}

151 We ground the concept of planetary well-being on accounts that link well-being with the satisfaction of basic needs as they are perceived from a neutral, non-subjective viewpoint. As described above, the needsbased accounts of well-being have been previously applied to human well-being (Doyal and Gough 1984; Max-Neef 1991; Gough 2017, 2015; Rice 2013), animal well-being (e.g. Broom 1991; Bartussek 1999; Singer

2002; Nussbaum 2006) and well-being of populations and ecosystems (e.g. Schlosberg 2007; Kortetmäki

2017). Yet, the overall diversity and number of different needs of various life forms prevents their integration into a singular calculus of well-being - or at least renders the possible results hardly applicable in practice. Therefore, instead of focusing on the needs themselves, we propose a focus on the systems and processes that are necessary for the satisfaction of the needs of diverse life forms on Earth. The focus on life-supporting systems and processes enables the integration of human and nonhuman well-being into a single framework. 
164 of biological hierarchies, from organisms (including humans) and populations and lineages to ecosystems -

165 that can all be considered as systems - and to Earth system and ecosystem processes. In general, life on

166 Earth can be understood as a set of interlinked, interdependent systems, and well-being at any level (be it

167 an individual organism, population, or ecosystem) as the integrity of that particular system. Crucially, the

168 functional integrity of any system (i.e., its well-being) is dependent on the satisfaction of its needs. Need

169 satisfiers are usually products of, or comprise interactions between, other systems. In other words, the

170 well-being of any particular system depends on inputs provided by other systems.

171 Table 1. The generic systems-oriented conceptual framework for well-being

\begin{tabular}{|c|c|}
\hline System & $\begin{array}{l}\text { System is an entity that is comprised of its components, that can be impacted by the } \\
\text { environment, has characteristic relations and interactions between its components, } \\
\text { and has system-specific characteristics and capacities that stem from the system } \\
\text { processes. }\end{array}$ \\
\hline $\begin{array}{l}\text { Critical system } \\
\text { processes }\end{array}$ & $\begin{array}{l}\text { System processes are recurring interactions between system components. } \\
\text { Interactions require inputs to function. Critical system processes are those without } \\
\text { which the system cannot continue its existence and realize its system-specific } \\
\text { characteristics and capacities. }\end{array}$ \\
\hline $\begin{array}{l}\text { Needs and need } \\
\text { satisfiers }\end{array}$ & $\begin{array}{l}\text { Needs are conditions of dependence on inputs (need satisfiers). Needs must be } \\
\text { satisfied for the critical system processes to function. }\end{array}$ \\
\hline Well-being & $\begin{array}{l}\text { The functional integrity of the system, or in other words the integrity of the critical } \\
\text { system processes, that allows the system to continue its existence and realize its } \\
\text { system-specific characteristics and capacities. }\end{array}$ \\
\hline
\end{tabular}


173 The conceptualization of well-being as the functional integrity of a system could, in principle, be applied

174 also to human artefacts (like motors), or to socially constructed systems (like economic systems). However,

175 as we do not consider such entities or systems to have moral considerability (value of their own that does

176 not depend on their value for humans), the well-being of artefacts and socially constructed systems falls

177 outside the scope of this manuscript.

178 The consideration of life on Earth as interlinkedand interacting systems directs attention to how the needs and well-being of different species and ecosystems are connected. For example, the needs of organisms have evolved over their evolutionary history in the context of ecosystems they inhabit. All organisms participate in many interactions, some of which are critical for their well-being (like feeding), while others may be detrimental and even lethal for them (like being fed upon), yet critical for some other organism(s). These interactions take place in ecosystems that in turn are dependent on the functioning of other, larger scale processes (e.g. climatic processes that affect temperatures and rainfall). Ecosystems further interact with other ecosystems; the examples of teleconnections between ecosystems include precipitation in terrestrial areas that depends in large part on evapotranspiration in distant forested areas (Van der Ent et al. 2010) and transport of energy and nutrients from marine to terrestrial ecosystems by migratory fish (Cederholm et al. 1999).

We define planetary well-being as a state in which the integrity of Earth system and ecosystem processes remains unimpaired to a degree that lineages can persist to the future as parts of ecosystems, and organisms (including humans) can realize their typical characteristics and capacities (see Table 2). Planetary well-being puts the emphasis on the integrity of Earth system and ecosystem level processes instead of organismal well-being, because at the organismal level life is rife with conflicts (such as predator-prey relations), and consequently not all organisms can 'be well' all the time. Death and senescence are normal parts of life's processes. However, the integrity of Earth system and ecosystem processes is fundamental for the survival and evolutionary potential of species and lineages - and for the existence and well-being of 
197 organisms and ecosystems they inhabit. We intend planetary well-being as a concept to promote respectful

198

199

200

\begin{tabular}{|c|c|}
\hline $\begin{array}{l}\text { Organismal (human and } \\
\text { nonhuman) well-being }\end{array}$ & $\begin{array}{l}\text { Organismal well-being is a state where an organism can realize its typical } \\
\text { characteristics and capacities. }\end{array}$ \\
\hline $\begin{array}{l}\text { Organismal needs and } \\
\text { need satisfiers }\end{array}$ & $\begin{array}{l}\text { Organismal needs are conditions of dependence on inputs (need satisfiers). } \\
\text { Needs must be satisfied for an organism to realize its typical characteristics } \\
\text { and capacities. Needs depend on the evolutionary history of the lineage in } \\
\text { which the organism belongs to. }\end{array}$ \\
\hline $\begin{array}{l}\text { Lineages, species, } \\
\text { populations }\end{array}$ & $\begin{array}{l}\text { A group of organisms with shared genetic ancestry that is distinct from other } \\
\text { such groups constitutes a lineage. For sexually reproducing organisms, species } \\
\text { and populations constitute lineages at global and local scales, respectively. }\end{array}$ \\
\hline Ecosystems & $\begin{array}{l}\text { Ecosystems are communities of organisms that interact with each other and } \\
\text { the abiotic environment. }\end{array}$ \\
\hline $\begin{array}{l}\text { Earth system and } \\
\text { ecosystem processes }\end{array}$ & $\begin{array}{l}\text { Processes relating to flows of energy and matter on Earth and to biotic } \\
\text { interactions in ecosystems. }\end{array}$ \\
\hline Planetary well-being & $\begin{array}{l}\text { Planetary well-being is a state in which the integrity of Earth system and } \\
\text { ecosystem processes remains unimpaired to a degree that lineages can persist } \\
\text { to the future as parts of ecosystems, and organisms (human and nonhuman) } \\
\text { can realize their typical characteristics and capacities. }\end{array}$ \\
\hline
\end{tabular}
ways of co-inhabiting Earth with nonhuman life so that both humans and nonhumans can achieve wellbeing in all parts of the world.

Table 2. Key concepts of planetary well-being. 
202 By the integrity of Earth system and ecosystem processes, we refer to the integrity of those flows of energy

203 and matter on Earth and biotic interactions in ecosystems that are critical for the satisfaction of the needs

204 of various organisms, populations and communities. These processes are manifold, and while there is

205 reasonable understanding of several important processes, such as nutrient cycles or pollination, it would be

206 foolhardy to assume that all important processes are known inside out. For example, the depletion of ozone

207 layer following the emission of chlorofluorocarbons came as a surprise to the scientific community

208 (Rowland 2006). Thus, all actions that significantly impact the flows of energy and matter are serious

209 concerns for planetary well-being, be it by resource use such as the human appropriation of $38 \%$ per cent

210 of net primary production on Earth (Running 2012), or by release of nutrients, greenhouse gases, or other

211 chemicals with possibly unknown effects. Similarly, excessive interference with natural ecosystems (as by

212 e.g. the destruction of natural habitats) or overharvesting of natural populations is likely to harm planetary

213 well-being.

214 While we have incomplete understanding of specific processes, we also have limited knowledge about interactions between and among Earth systems, ecosystems, and human-created systems (e.g. Reid et al. 2010; Liu et al. 2015; Liu et al. 2018). Many of these interactions are likely to magnify each other: risks of

217 causing irreversible changes to Earth system are higher in studies that consider interactions between systems or processes (e.g. Lade et al. 2019). Given that there are profound uncertainties regarding the consequences of human interference with Earth system and ecosystem processes, abstinence from potential harm even in the absence of the proof of harm (the precautionary principle (e.g. Cameron and Abouchar 1991) — is often a safer strategy to avoid worsening global environmental problems.

222 When defining planetary well-being, we underscore the persistence of lineages (e.g. species and populations) as parts of ecosystems for both practical and moral reasons. As discussed above, the processes contributing to the satisfaction of the needs of various living systems are not fully understood. However, it 
225 is possible to monitor the status of populations and species, and this gives a good indication of whether the

226 needs of lineages and organisms within them can be adequately satisfied. For example, if population sizes

227 show unusual persistent declines, this usually indicates a failure of some critical process(es) relating to need

228 satisfaction. Viability of species and populations thus indicates the integrity of the critical, but sometimes

229 intractable, processes that underpin well-being at all levels.

230 As a non-anthropocentric and holistic concept, planetary well-being aligns with views that consider the

231 survival of lineages to be an end in itself (Rolston 1985). Currently the human exploitation of and

232 interference with ecosystems harms vast numbers of other species and populations, with the estimated

233 number of species considered to be under risk of extinction being up to 1 million (IPBES 2019). However,

234 humans also have needs that have to be satisfied for human well-being. The satisfaction of some of these

235 needs - like the need for adequate nutrition - is practically impossible without some interference with

236 ecosystems. From the planetary well-being point of view, the level of the human interference with

237 ecosystems must not compromise the ability of other species and lineages to persist in these ecosystems to

238 the future (i.e., it must not increase their risk of extinction). Achieving planetary well-being necessitates

239 that human basic needs are satisfied in a way that does not compromise the capacity for nonhuman nature

240 (its entities) to achieve well-being. An important step in this direction is to prioritize the satisfaction of basic

241 human needs over the satisfaction of desires and wants that have a negative impact on nonhuman nature.

242 Putting the CONCEPT TO USE

243 As a concept, planetary well-being has potential to contribute positively to the transformational changes

244 towards sustainability (sustainability transition) by helping to navigate trade-offs between human and

245 nonhuman needs, providing measures and targets for decision making, and bridging divergent worldviews.

246 RECONCILING HUMAN NEEDS WITH PLANETARY WELL-BEING 
247 The idea of needs and need satisfiers is integral to the concept of planetary well-being. While the satisfaction of needs is necessary for the well-being of any system, the relationship between the needs and need satisfiers is contingent: needs can often be satisfied in various ways. Importantly however, when it comes to securing the satisfaction of the needs of nonhuman nature, the human action mainly concerns safeguarding or not harming the Earth system and ecosystem processes as far as possible. Active measures are often unnecessary; the well-being of 'wild' nonhuman nature is often best served by "deconstructing the impediments to nature's own capabilities [or capacities] to fully and continually function" (Schlosberg 2007, p. 150). Domesticated animals and ecosystems (e.g. gardens) on the other hand depend on human provision for their continued existence. While we do not discuss the status of domesticated nature (that raises distinct normative questions) here, we note that many domesticated animals are not able to realize their characteristics and capacities, and ecosystem modification (e.g. building a garden) may interfere with ecosystem processes that are critical for the needs satisfaction of wild nonhuman nature.

When it comes to the satisfaction of human needs, it is necessary to reflect upon what the quality of life as associated with well-being - entails, especially when it comes to consumption of material goods (IPBES 2019). Humans are complex social beings and different scientific fields provide different accounts of human well-being with different points of emphasis. However, when the question is how societies can organize and operate in ways that best support human well-being, it is necessary to approach well-being in a way that is institutionally applicable and meaningful for governance and policymaking. This directs attention to the needs-based, non-subjective conceptions of human well-being. They are grounded on the assumption that all humans, like all organisms, have certain universal basic needs that have to be satisfied in order to have a good life, to avoid serious harm, and to be able to act fully in life: the satisfaction of needs is a necessary (though not always sufficient) condition for well-being. Although the articulation of the needs varies between different authors (e.g. Doyal and Gough 1984; Max-Neef 1991; Rice 2013; Gough 2017) and some accounts emphasize the capabilities to achieve various functionings that contribute to needs satisfaction 
271 (Nussbaum and Sen 1993; Nussbaum 2011), they all share the key elements of the need for physical and

272 mental health, for relationships, and for autonomy in action and thought. Satisfaction of these key elements

273 requires (that aforementioned authors suggest to include, for example, adequate nutrition, safety, and at

274 least some kind of health care and education. When approached from a human perspective, planetary well-

275 being is a state in which the organization of human systems simultaneously allows human needs to be met,

276 and the impact on Earth and ecosystem processes is limited so that lineages can persist to the future as

277 parts of ecosystems and organisms can realize their typical characteristics and capacities.

278 The social scientific, needs-based approach to human well-being has several features that are relevant for 279 discussions about sustainability (Gough 2017). First, many human needs are objective: regardless of 280 subjective experiences, it is empirically verifiable that for example malnourishment or lack of caring relationships causes serious harm to individuals (this is not to deny that needs will always be subjectively interpreted at the individual level). Second, human needs are plural: they include material, social and psychological aspects. Third, human needs are non-substitutable, e.g. it is not possible to satisfy a need for healthy nutrition with more education. Fourth, human needs are, in principle, satiable: it is possible to identify a level of needs satisfaction that would suffice for adequate well-being. However, in consumerist societies, being able to 'live without shame' requires a level of consumption that matches - or exceeds - the consumption of others, and thus drives ever-increasing consumption. Yet at the societal level this does not lead to increasing social well-being but to fragmentation and anomie (Jackson 2017 p. 124). Fifth, the needs are substantially universal, applying to people in different places and at different times, though the ways of satisfying them vary in different times and cultures: even the objective and universal needs are not 'absolute' but involve relative, context-specific aspects. The precise level where a need is satisfied may vary across individuals and contexts (consider the differentiated needs for nutrition or, for example, belongingness); and some space of choice for needs satisfaction and actual doings in one's individual life are required for freedom (Nussbaum and Sen 1993). The conception of universal needs and average 
requirements for their satisfaction at individual level, nevertheless, provide a very useful tool for guiding and evaluating societal activities in directions that support human well-being. This gives a foundation for considering the well-being of both present and future generations.

The idea of satiable human needs means that good, fulfilling and dignified life can be achieved with limited consumption sufficient to meet the material needs, together with satisfaction of non-material needs like significant primary relationships, leisure, and social participation (Max-Neef 1991; Gough 2017).

Acknowledged, the levels of subjectively experienced well-being in such scenarios of reduced material consumption are not well known, though similar changes have historically occurred in societies especially during the post-war periods. Suggestions for achieving well-being with significantly lower material consumption, however, are difficult. They are in stark contrast with consumerist and materialistic societies, where ever-increasing production and consumption fuel the dynamics of the economy, where well-being is understood as the realization of insatiable human preferences, and where good life is understood as rising material standard of living. In contrast, achieving planetary well-being requires reducing consumption of material goods that are not relevant for human needs (or that directly harm well-being). Global and regional equality considerations also necessitate a focus on the well-being and satisfaction of both material and non-material needs of all, instead of increased well-being for the already privileged.

It is also important to note that human material needs can be satisfied in many ways (i.e. by different need satisfiers), with different impacts on planetary well-being. This directs attention to the sustainability of production. One relevant example that has received much research attention is the human need for protein, which can be satisfied in various ways that differ in their impacts on planetary well-being. When there are multiple alternatives for fulfilling human needs, those with the least harmful impacts on planetary well-being and the most beneficial impacts on needs satisfaction globally, between and within human communities, should be prioritized in order to maximize planetary well-being. Simultaneously, it should be 
318 kept in mind that the best need satisfiers may be different in different locations and societies and should

319 hence remain open to community-level reflections and individual freedom of choice (cf. Nussbaum and Sen

320 1993). Also, understanding and propping up the factors that promote pro-environmental behaviour

321 (including lower material consumption) at individual levels is crucial. Related behaviour patterns are known

322 to be influenced by, for example, institutional, economic, social, emotional, motivational, value, attitude

323 and awareness factors (Kollmus \& Agyeman, 2002).

\section{MEASURES AND TARGETS FOR DECISION MAKING}

The rapid declines in animal population sizes and increases in extinction rates manifest the lack of wellbeing of nonhuman life on Earth today. Improving planetary well-being necessitates halting or transforming the harmful human activities and fostering actions to restore the integrity of Earth system and ecosystem processes that have been impaired by past actions. Ecological remediation, rehabilitation and restoration represent tools for advancing this aim at local levels (Gann et al. 2019). Data about the national/regional drivers of extinction threats can be a valuable source of information to identify those human practices (such as livestock farming and ranching, logging and wood harvesting, and the release of effluents) that are most damaging to planetary well-being at regional and national scales, and to justify urgent changes in these actions. This information (direct drivers of extinction threat) is available in national/regional IUCN Red Lists (https://www.iucnredlist.org/) though the coverage is not yet global. Information from the IUCN Red Lists also helps to identify those ecosystems and processes that require most urgent protection and restoration actions to improve the viability of threatened species and populations.

From Red Lists, it is also possible to construct indices that can be used as surrogate measures for regional and global states and trends in planetary well-being, at least as far as wild organisms are concerned. The Red List index (RLI) calculates the average threat status of the set of species included in the index. RLI takes values between 0 (all species extinct) and 1 (all species in the 'Least Concern' category). As we define 
341 planetary well-being also in terms of persistence of lineages to the future (see Table 2), RLIs for well-chosen

342 sets of organisms at regional and global scales could be used to measure the status of planetary well-being

343 at different scales (however, extinction threats due to non-human causes, e.g. volcanic eruptions and

344 natural diseases, should not count negatively to the score). Regional and global Red List Index values

345 approaching 1 could also serve as intuitive, specific and measurable targets for efforts to stop and reverse

346 current declines in biodiversity, similarly to the IPCC target of limiting global warming to $1.5^{\circ} \mathrm{C}$.

347 Whether planetary well-being will be achieved or not ultimately depends on how human societies organize

348 their systems for human needs satisfaction. This is the crucial question and task at hand. It requires better

349 tools for evaluating the impacts of different policies and practices for achieving more equal human well-

350 being alongside improved planetary well-being: in the long run, there can be no human well-being without

351 planetary well-being.

\section{BRIDGING DIVERGENT WORLDVIEWS}

353 We believe that planetary well-being could enrich the conceptual toolbox to foster transformation to a

354 world that promotes well-being more equally by unifying systems-thinking and both human and nonhuman

355 well-being to a single, intuitively appealing concept. Unlike many related concepts, planetary well-being

356 avoids anthropocentrism, yet allows for discussions about human and nonhuman well-being in a common

357 framework. The emphasis on well-being as the satisfaction of basic needs helps draw attention to the plight

358 of underprivileged human communities and socio-economic groups and to the literally existential plight of

359 nonhuman nature.

360 The concept speaks to different scientific disciplines, which we have tested during the process of writing

361 this work, and is approachable to different domains in the public sector, at different levels, as well as to civil

362 society and private sector actors whose cooperation is required for solving the ecological crisis. It aims not

363 to replace previous conceptual frameworks but, rather, to supplement them by providing a multi-scalar and 
364 non-anthropocentric approach to discussing the pressing questions of environmental and social challenges.

365 Planetary well-being - the opportunity for both humans and nonhumans to have their needs satisfied now 366 and in the future - can, and should, become the ultimate goal of human activities and cooperation.

367

368 SUPPLEMENTARY ITEMS

369

370

1. Neighbouring concepts

371

372 ACKNOWLEDGEMENTS

373 RD and JP are supported by the Kone Foundation. Writing has been supported by the Strategic

374 Research Council Finland grant 327284 (TK) and 313015 (MS).

375

376

377 REFERENCES

378

379

380

Alvaredo, Facundo, Lucas Chancel, Thomas Piketty, Emmanuel Saez, and Gabriel Zucman. 2018. World

381 inequality report 2018 (Belknap Press). 
382

383

384

385

386

387

388

389

390

391

392

393

394

395

396

397

398

399

400

401

402

403

404

405

Assembly, UN General. 2015. 'Transforming our world: the 2030 Agenda for Sustainable Development', Division for Sustainable Development Goals: New York, NY, USA.

Bartussek, H. 1999. 'A review of the animal needs index (ANI) for the assessment of animals' well-being in the housing systems for Austrian proprietary products and legislation', Livestock Production Science, 61: 179-92.

Broom, Donald M. 1991. 'Animal welfare: concepts and measurement', Journal of animal science, 69: 416775.

Bunge, Mario. 2003. Emergence and convergence: Qualitative novelty and the unity of knowledge (University of Toronto Press).

- - . 2004. 'How does it work? The search for explanatory mechanisms', Philosophy of the social sciences, 34: $182-210$.

Cameron, James, and Juli Abouchar. 1991. 'The precautionary principle: a fundamental principle of law and policy for the protection of the global environment', BC Int'l \& Comp. L. Rev., 14: 1.

Cederholm, C. Jeff, Matt D. Kunze, Takeshi Murota, and Atuhiro Sibatani. 1999. 'Pacific Salmon Carcasses: Essential Contributions of Nutrients and Energy for Aquatic and Terrestrial Ecosystems', Fisheries, 24: 6-15.

Crutzen, Paul J, and Eugene F Stoermer. 2000. 'The "Anthropocene"', IGBP Global Change Newsletter: 1718.

Díaz, Sandra, Sebsebe Demissew, Julia Carabias, Carlos Joly, Mark Lonsdale, Neville Ash, Anne Larigauderie, Jay Ram Adhikari, Salvatore Arico, András Báldi, Ann Bartuska, Ivar Andreas Baste, Adem Bilgin, Eduardo Brondizio, Kai M. A. Chan, Viviana Elsa Figueroa, Anantha Duraiappah, Markus Fischer, Rosemary Hill, Thomas Koetz, Paul Leadley, Philip Lyver, Georgina M. Mace, Berta Martin-Lopez, Michiko Okumura, Diego Pacheco, Unai Pascual, Edgar Selvin Pérez, Belinda Reyers, Eva Roth, Osamu Saito, Robert John Scholes, Nalini Sharma, Heather Tallis, Randolph Thaman, Robert 
Watson, Tetsukazu Yahara, Zakri Abdul Hamid, Callistus Akosim, Yousef Al-Hafedh, Rashad Allahverdiyev, Edward Amankwah, Stanley T. Asah, Zemede Asfaw, Gabor Bartus, L. Anathea Brooks, Jorge Caillaux, Gemedo Dalle, Dedy Darnaedi, Amanda Driver, Gunay Erpul, Pablo EscobarEyzaguirre, Pierre Failler, Ali Moustafa Mokhtar Fouda, Bojie Fu, Haripriya Gundimeda, Shizuka Hashimoto, Floyd Homer, Sandra Lavorel, Gabriela Lichtenstein, William Armand Mala, Wadzanayi Mandivenyi, Piotr Matczak, Carmel Mbizvo, Mehrasa Mehrdadi, Jean Paul Metzger, Jean Bruno Mikissa, Henrik Moller, Harold A. Mooney, Peter Mumby, Harini Nagendra, Carsten Nesshover, Alfred Apau Oteng-Yeboah, György Pataki, Marie Roué, Jennifer Rubis, Maria Schultz, Peggy Smith, Rashid Sumaila, Kazuhiko Takeuchi, Spencer Thomas, Madhu Verma, Youn Yeo-Chang, and Diana Zlatanova. 2015. 'The IPBES Conceptual Framework - connecting nature and people', Current Opinion in Environmental Sustainability, 14: 1-16.

Díaz, Sandra, Josef Settele, Eduardo S. Brondízio, Hien T. Ngo, John Agard, Almut Arneth, Patricia Balvanera, Kate A. Brauman, Stuart H. M. Butchart, Kai M. A. Chan, Lucas A. Garibaldi, Kazuhito Ichii, Jianguo Liu, Suneetha M. Subramanian, Guy F. Midgley, Patricia Miloslavich, Zsolt Molnár, David Obura, Alexander Pfaff, Stephen Polasky, Andy Purvis, Jona Razzaque, Belinda Reyers, Rinku Roy Chowdhury, Yunne-Jai Shin, Ingrid Visseren-Hamakers, Katherine J. Willis, and Cynthia N. Zayas. 2019. 'Pervasive human-driven decline of life on Earth points to the need for transformative change', Science, 366: eaax3100.

Doyal, Len, and lan Gough. 1984. 'A theory of human needs', Critical Social Policy, 4: 6-38.

Dryzek, John S. 2005. The Politics of the Earth: Environmental Discourses (Oxford University Press: Oxford). Dryzek, John S, and Jonathan Pickering. 2018. The politics of the Anthropocene (Oxford University Press). Environment, UN. 2019. "Global Environment Outlook - GEO-6: Healthy Planet, Healthy People." In. Nairobi. 
429

430

431

432

433

434

435

436

437

438

439

440

441

442

443

444

445

446

447

448

449

450

451

Gann, George D., Tein McDonald, Bethanie Walder, James Aronson, Cara R. Nelson, Justin Jonson, James G. Hallett, Cristina Eisenberg, Manuel R. Guariguata, Junguo Liu, Fangyuan Hua, Cristian Echeverría, Emily Gonzales, Nancy Shaw, Kris Decleer, and Kingsley W. Dixon. 2019. 'International principles and standards for the practice of ecological restoration. Second edition', Restoration Ecology, 27: S1-S46.

Gough, lan. 2015. 'Climate change and sustainable welfare: the centrality of human needs', Cambridge Journal of Economics, 39: 1191-214.

- - - 2017. 'Recomposing consumption: defining necessities for sustainable and equitable well-being', Philosophical Transactions of the Royal Society A: Mathematical, Physical and Engineering Sciences, 375: 20160379.

Hornborg, Alf. 1998. 'Towards an ecological theory of unequal exchange: articulating world system theory and ecological economics', Ecological Economics, 25: 127-36.

IPBES. 2018. "Summary for policymakers of the assessment report on land degradation and restoration of the Intergovernmental Science-Policy Platform on Biodiversity and Ecosystem Services." In, edited by Luca Montanarella, Robert Scholes and Anastasia Brainich, 744 pages. Bonn, Germany: Secretariat of the Intergovernmental Science-Policy Platform on Biodiversity and Ecosystem Services.

- - . 2019. "Summary for policymakers of the global assessment report on biodiversity and ecosystem services of the Intergovernmental Science-Policy Platform on Biodiversity and Ecosystem Services." In IPBES Secretariat: Bonn, Germany, edited by S Díaz, J Settele, ES Brondízio, HT Ngo, M Guèze, J Agard, A Arneth, P Balvanera, KA Brauman and SHM Butchart, 56.

IPCC. 2019. "Climate Change and Land: an IPCC special report on climate change, desertification, land degradation, sustainable land management, food security, and greenhouse gas fluxes in terrestrial 
452

453

454

455

456

457

458

459

460

461

462

463

464

465

466

467

468

469

470

471

472

473

474

ecosystems." In, edited by PR Shukla, J Skea, E Calvo Buendia, V Masson-Delmotte, HO Pörtner, DC Roberts, P Zhai, Raphael Slade, Sarah Connors and Renée Van Diemen.

Jackson, Tim. 2017. Prosperity without growth: foundations for the economy of tomorrow (Routledge).

Keyes, Corey LM. 2005. 'Mental illness and/or mental health? Investigating axioms of the complete state model of health', Journal of consulting and clinical psychology, 73: 539.

Kohler, Florent, Timothy G Holland, Janne S Kotiaho, Maylis Desrousseaux, and Matthew D Potts. 2019. 'Embracing diverse worldviews to share planet Earth', Conservation Biology, 33: 1014-22.

Kokko, Katja, Anni Korkalainen, Anna-Liisa Lyyra, and Taru Feldt. 2013. 'Structure and continuity of wellbeing in mid-adulthood: A longitudinal study', Journal of Happiness Studies, 14: 99-114.

Kollmuss, Anja, and Julian Agyeman. "Mind the gap: why do people act environmentally and what are the barriers to pro-environmental behavior?." Environmental education research 8.3 (2002): 239-260.

Kortetmäki, Teea. 2017. 'Applying the capabilities approach to ecosystems: Resilience as ecosystem capability', Environmental Ethics, 39: 39-56.

- - . 2018. 'Can Species Have Capabilities, and What if They Can?', Journal of Agricultural and Environmental Ethics, 31: 307-23.

Liu, Jianguo, Vanessa Hull, H Charles J Godfray, David Tilman, Peter Gleick, Holger Hoff, Claudia Pahl-Wostl, Zhenci Xu, Min Gon Chung, and Jing Sun. 2018. 'Nexus approaches to global sustainable development', Nature Sustainability, 1: 466-76.

Liu, Jianguo, Harold Mooney, Vanessa Hull, Steven J Davis, Joanne Gaskell, Thomas Hertel, Jane Lubchenco, Karen C Seto, Peter Gleick, and Claire Kremen. 2015. 'Systems integration for global sustainability', Science, 347.

Malm, Andreas, and Alf Hornborg. 2014. 'The geology of mankind? A critique of the Anthropocene narrative', The Anthropocene Review, 1: 62-69. 
475

476

477

478

479

480

481

482

483

484

485

486

487

488

489

490

491

492

493

494

495

496

497

498

Max-Neef, Manfred A. 1991. Human scale development : conception, application and further reflections (The Apex Press: New York).

Newsome, Kirsty, Philip Taylor, Jennifer Bair, and Al Rainnie. 2015. Putting labour in its place: labour process analysis and global value chains (Palgrave).

Nussbaum, Martha C. 2006. Frontiers of justice: Disability, nationality, species membership (Harvard University Press).

Nussbaum, Martha C. 2011. Creating Capabilities: The Human Development Approach (Harvard University Press: Cumberland, UNITED STATES).

Nussbaum, Martha, and Amartya Sen (ed.)^(eds.). 1993. The quality of life (Clarendon Press).

O’Neill, Daniel W, Andrew L Fanning, William F Lamb, and Julia K Steinberger. 2018. 'A good life for all within planetary boundaries', Nature Sustainability, 1: 88-95.

Ostrom, Elinor. 2009. 'A general framework for analyzing sustainability of social-ecological systems', Science, 325: 419-22.

Prescott-Allen, Robert. 2001. The wellbeing of nations (Island Press).

Reid, W. V., D. Chen, L. Goldfarb, H. Hackmann, Y. T. Lee, K. Mokhele, E. Ostrom, K. Raivio, J. Rockström, H. J. Schellnhuber, and A. Whyte. 2010. 'Earth System Science for Global Sustainability: Grand Challenges', Science, 330: 916-17.

Rice, Christopher M. 2013. 'Defending the Objective List Theory of Well-Being', Ratio, 26: 196-211.

Rockström, Johan, Will Steffen, Kevin Noone, Åsa Persson, F. Stuart Chapin lii, Eric F. Lambin, Timothy M. Lenton, Marten Scheffer, Carl Folke, Hans Joachim Schellnhuber, Björn Nykvist, Cynthia A. de Wit, Terry Hughes, Sander van der Leeuw, Henning Rodhe, Sverker Sörlin, Peter K. Snyder, Robert Costanza, Uno Svedin, Malin Falkenmark, Louise Karlberg, Robert W. Corell, Victoria J. Fabry, James Hansen, Brian Walker, Diana Liverman, Katherine Richardson, Paul Crutzen, and Jonathan A. Foley. 2009. 'A safe operating space for humanity', Nature, 461: 472. 
499

500 501

Rolston, Holmes. 1985. 'Duties to endangered species', Bioscience, 35: 718-26.

-- - 2002. "What do we mean by the intrinsic value and integrity of plants and animals?" In.: Colorado State University. Libraries.

Rowland, F. Sherwood. 2006. 'Stratospheric ozone depletion', Philosophical Transactions of the Royal Society B: Biological Sciences, 361: 769-90.

Running, Steven W. 2012. 'A measurable planetary boundary for the biosphere', Science, 337: 1458-59.

Schlosberg, David. 2007. Defining environmental justice: theories, movements, and nature (Oxford University Press: Oxford).

Singer, P. 2002. Animal liberation.

Steffen, Will, Wendy Broadgate, Lisa Deutsch, Owen Gaffney, and Cornelia Ludwig. 2015. 'The trajectory of the Anthropocene: the great acceleration', The Anthropocene Review, 2: 81-98.

Steffen, Will, Katherine Richardson, Johan Rockström, Sarah E Cornell, Ingo Fetzer, Elena M Bennett, Reinette Biggs, Stephen R Carpenter, Wim De Vries, and Cynthia A De Wit. 2015. 'Planetary boundaries: Guiding human development on a changing planet', Science, 347.

Van der Ent, Rudi J, Hubert HG Savenije, Bettina Schaefli, and Susan C Steele-Dunne. 2010. 'Origin and fate of atmospheric moisture over continents', Water Resources Research, 46.

van der Esch, Stefan, Ben ten Brink, Elke Stehfest, Michel Bakkenes, Annelies Sewell, Arno Bouwman, Johan Meijer, Henk Westhoek, Maurits van den Berg, and Gert Jan van den Born. 2017. 'Exploring future changes in land use and land condition and the impacts on food, water, climate change and biodiversity: scenarios for the UNCCD Global Land Outlook'.

Warren, Mary Anne. 1997. Moral status: Obligations to persons and other living things (Clarendon Press).

Watson, James E M., Danielle F Shanahan, Moreno Di Marco, James Allan, William F Laurance, Eric W Sanderson, Brendan Mackey, and Oscar Venter. 2016. 'Catastrophic Declines in Wilderness Areas Undermine Global Environment Targets', Current Biology, 26: 2929-34. 
523 WCED. 1987. Our common future (Oxford University Press: Oxford).

524 Wemelsfelder, Françoise. 1997. 'The scientific validity of subjective concepts in models of animal welfare', $525 \quad$ Applied Animal Behaviour Science, 53: 75-88.

526 Willemen, Louise, Nichole N Barger, Ben Ten Brink, Matthew Cantele, Barend FN Erasmus, Judith L Fisher, 527 Toby Gardner, Timothy G Holland, Florent Kohler, and Janne S Kotiaho. 2020. 'How to halt the 528 global decline of lands', Nature Sustainability, 3: 164-66.

529 Winter, Deborah Du Nann, and Susan M Koger. 2004. The psychology of environmental problems $530 \quad$ (Psychology Press).

531 WWF. 2020. "Living Planet Report 2020 - Bending the curve of biodiversity loss." In, edited by R.E.A. Almond, M. Grooten and T. Petersen. Gland, Switzerland.

533

534 